\title{
TINGKAT PEDIDIKAN DENGAN PERILAKU IBU DALAM MELAKUKAN PIJAT BAYI
}

\author{
${ }^{1}$ Nurwinda Saputri, ${ }^{2}$ Tatu Sholeha \\ ${ }^{1}$ Dosen Prodi D-III Kebidanan, STIKes Muhammadiyah Pringsewu, Jl. Makam KH Ghalib No 112 Lampung; \\ 2. Alumni STIKes Muhammadiyah Pringsewu \\ Email: ${ }^{1}$ nurwindasaputri17@gmail.com, ${ }^{2}$ sholehatatu123@gmail.com
}

\begin{abstract}
ABSTRAK
Pemijatan bayi oleh ibu mempunyai makna sendiri karena sangat berpengaruh terhadap hubungan batin atau hubungan kejiwaan diantara ibu dan anak. Bagi sang bayi pijatan ibu dapat dirasakan sebagai sentuhan kasih sayang yang sangat berarti bagi pembentukan pribadinya dikemudian hari. Aspek pendidikan juga memegang peranan penting dalam pemijatan bayi. Semakin tinggi pendidikan, semakin mudah pula menerima dan mengakses informasi. Penting sekali bagi setiap ibu bayi untuk mempelajari cara-cara praktis dan yang dianjurkan mengenai teknis pemijatan bayi. Pemijatan bayi oleh ibunya sendiri juga mampunyai makna sendiri karena sangat berpengaruh terhadap hubungan batin atau hubungan kejiwaan diantara ibu dan anak. Desain penelitian ini adalah survei analitik dengan menggunakan pendekatan crossectional, yaitu variabel sebab atau risiko dan akibat atau kasus yang terjadi pada objek penulisan diukur atau dikumpulkan secara simultan. Populasi yang diamati dalam penelitian ini adalah semua ibu yang memiliki bayi di Desa Batu Raja Kecamatan Way Lima Kabupaten Pesawaran. Pengambilan sampel dalam Penulisan ini adalah dengan metode total sampling dimana seluruh anggota populasi dijadikan sampel yaitu sebanyak 42 orang.
\end{abstract}

Kata Kunci : Tingkat Pendidikan, Perilaku Ibu, Pijat Bayi

\section{PENDAHULUAN}

Pemijatan bayi oleh ibu mempunyai makna sendiri karena sangat berpengaruh terhadap hubungan batin atau hubungan kejiwaan diantara ibu dan anak. Bagi sang bayi pijatan ibu dapat dirasakan sebagai sentuhan kasih sayang yang sangat berarti bagi pembentukan pribadinya dikemudian hari (Roesli, 2009). Namun Mitos dimasyarakat pada perawatan bayi yang tetap dipercaya, contoh: masih banyak ibu yang enggan untuk melakukan pemijatan secara rutin kepada bayi apalagi diawal-awal kelahiran karena mereka beranggapan bahwa bayi tidak boleh sering dipijat, badan bayi masih lemah atau alasan lain yang tidak pernah dibuktikan. Padahal sentuhan pada bayi pada awal-awal kelahiran bisa memberikan pengaruh positif pada pertumbuhan bayi (Nestle,2005).

Pijat bayi merupakan suatu tradisi, terutama bagi orang Jawa yang sampai saat ini masih terus dilestarikan. Meski demikian, masih banyak praktik pijat bayi yang ternyata berbahaya bahkan berujung pada kematian. Untuk menyosialisasikan cara pemijatan bayi yang benar, Rumah Sakit Akademik (RSA) UGM menyelenggarakan lomba pijat bayi. Direktur Pelayanan Medis, Penunjang Medis dan Keperawatan RSA UGM, Prof. dr Sunartini Hapsara, Sp.A(K)., Ph.D., mengatakan Pijat bayi baik untuk kesehatan bayi asalkan pelaksanaan sesuai dengan cara yang benar. Pijatan pada bayi dapat dijadikan semacam rangsangan agar tumbuh kembang bayi lebih optimal. Namun kesalahan sedikit saat pemijatan, bisa menghilangkan nyawa sang bayi. Yang paling sering terjadi ialah pendarahan otak akibat pemijatan terlalu keras di area kepala.Padahal kepala menjadi salah satu bagian dari bayi yang tidak boleh dipijat (Sunartini, 2009). Kepala dan perut merupakan bagian yang sama sekali tidak boleh dipijat. Untuk menghindari dampak yang membahayakan bagi si bayi. Pasalnya angka kematian bayi akibat kesalahan pemijatan yang pernah ditangani oleh RSUP Dr Sardjito dan sudah dilaporkan tiap tahunnya mencapai 45 anak meninggal. Dan setiap tahunnya rata-rata ada 10 bayi yang mengalami pendarahan otak dan organ bagian dalam perut yang mengalami kelainan. Setelah ditelusuri, rata-rata akibat bayi yang dipijat dengan cara tidak benar.

Berdasarkan Laporan Dinas Kesehatan Kabupaten Pesawaran, jumlah bayi kabupaten pesawaran sebanyak 568 orang pada tahun 2013. berdasarkan data dari Puskesmas Kota Dalam jumalah balita didesa batu raja pada tahun 2013 sebanyak 45 orang, dan hanya 30 $\%$ bayi yang dilakukan pijat bayi dan pemijatan dilaksanakan didukun bayi. Berdasarkan profil Puskesmas Kota Dalam jumlah penduduk di Desa Batu Raja sebanyak 23.872 ibu yang bisa membaca pada tahun 2013 sebanyak 3.515 dan rata-rata berpendidikan lulus SD $45 \%$, SMP 25 $\%$,SMA $20 \%$, Perguruan tinggi $1 \%$.

Aspek pendidikan juga memegang peranan penting dalam pemijatan bayi. Semakin tinggi pendidikan, semakin mudah pula menerima dan mengakses informasi. Pendidikan juga data menghambat 
perkembangan sikap seseorang dalam penerimaan informasi dan nilai-nilai yang baru diperkenalkan (Mubarak, 2011). Orang tua terdidik mempunyai kemampuan menyerap informasi yang berkaitan dengan kesehatan khususnya pijat bayi. Pelaksanaan pijat bayi sangat berkaitan dengan perilaku ibu dalam perawatan anak. Salah satu faktor yang mempengaruhi adalah pengetahuan, dimana perilaku yang didasari oleh pengetahuan akan bersifat langgeng (Notoatmodjo, 2010).

Penting sekali bagi setiap ibu bayi untuk mempelajari cara-cara praktis dan yang dianjurkan mengenai teknis pemijatan bayi. Pemijatan bayi oleh ibunya sendiri juga mampunyai makna sendiri karena sangat berpengaruh terhadap hubungan batin atau hubungan kejiwaan diantara ibu dan anak. Bagi sang bayi pijatan ibu dapat dirasakan sebagai sentuhan kasih sayang yang sangat berarti bagi pembentukan pribadinya dikemudian hari (Roesli, 2013).

Pada penelitian Nora Safrina (2013) di BPS Jauniwati Indrapuri Kabupaten Aceh Besar Tahun 2013 di dapatkan data dari hasil penelitian pada 28 responden dewasa akhir dengan pengetahuannya rendah sebanyak $60,7 \%$, dari 21 responden berpendidikan menengah dengan pengetahuannya rendah sebanyak $100 \%$, dari 23 responden yang status pekerjaan non PNS dengan pengetahuannya rendah sebanyak $95,7 \%$ dan dari 22 responden yang tidak pernah melakukan pijat bayi dengan pengetahuannya rendah sebanyak $100 \%$. Hasil uji statistik chisquare diperoleh nilai kemaknaan $p$-value $=$ $0,000(p \leq 0,05)$ sehingga ada pengaruh antara pendidikan, pekerjaan dan pengalaman dengan pengetahuan ibu tentang pijat bayi. Hal ini menunjukan bahwa ada pengaruh antara pendidikan, pekerjaan dan pengalaman terhadap pengetahuan tentang pijat bayi.

Dari hasil pra survei dengan cara mewawancarai 18 orang ibu yang memiliki bayi didapatkan 4 dari 18 ibu kurang mengetahui pijat bayi serta belum mengetahui manfaat lebih jauh dari pijat bayi dan belum memahami bagaimana memijat bayi yang benar sehingga tidak bisa melakukan pemijatan secara mandiri. Sebagian besar ibu memijatkan bayi di dukun, seharusnya ibu mendapat pendidikan kesehatan mengenai cara memijat bayi yang diajarkan oleh bidan atau perawat setempat, karena jauh dari fasilitas kesehatan maka ibu tidak tahu cara memijat bayi sendiri. Sementara itu 2 dari 18 ibu mengatakan takut untuk melakukan pijat bayi karena menurut mereka bayi yang baru lahir tulangnya lembek dan apabila dipijat takut bisa berakibat fatal yaitu patah.

\section{METODE}

Desain penelitian ini adalah survei analitik dengan menggunakan pendekatan crossectional. Variabel yang digunana independen dan dependen. Populasi pada penelitian ini adalah semua ibu yang memiliki bayi di Desa Batu Raja Kec. Way Halim, Kab. Pesawaran. Sampel berjumlah 42 orang. Pengumpulan data Penelitian ini dilakukan di Desa Batu Raja Kecamatan Way Lima Kabupaten Pesawaran Bulan Maret Tahun 2014. Dalam penelitian ini data yang digunakan adalah data primer yaitu dengan mengobservasi dan mewawancarai langsung ibu dengan menggunakan lembar kuisioner berisikan pertanyaan tentang tingkat pendidikan ibu dengan perilaku ibu dalam terapi pijat bayi.

\section{HASIL}

a. Analisis Univariat

$\begin{array}{lll}\text { - Distribusi } & \text { Frekuensi Tingkat } \\ \text { Pendidikan } & \end{array}$

Tabel 1. Distribusi Frekuensi Berdasarkan Tingkat Pendidikan Ibu di Desa Baturaja Kecamatan Way Lima Kabupaten Pesawaran

\begin{tabular}{ccc}
\hline Pendidikan & Frekuensi & Persentase (\%) \\
\hline Rendah & 19 & 45,2 \\
\hline Sedang & 18 & 42,9 \\
\hline Tinggi & 5 & 11,9 \\
\hline Jumlah & $\mathbf{4 2}$ & $\mathbf{1 0 0}$
\end{tabular}

Sumber : data primer 201

Sebagian besar pendidikan ibu memiliki pendidikan yang rendah yaitu sebanyak 19 responden $(45,2 \%)$.

\section{- Distribusi Frekuensi Pijat Bayi}

Tabel 2. Distribusi Frekuensi Berdasarkan Perilaku ibu dalam melakukan pijat bayi di Desa Baturaja Kecamatan Way Lima Kabupaten Pesawaran

\begin{tabular}{lcc}
\hline Pijat Bayi & Frekuensi & Persentase (\%) \\
\hline Tidak melakukan & 23 & 54,8 \\
\hline Melakukan & 19 & 45,2 \\
\hline Jumlah & $\mathbf{4 2}$ & $\mathbf{1 0 0}$ \\
\hline
\end{tabular}

Sumber : data primer 2014

Sebagian ibu tidak melakukan pemijatan bayi secara mandiri yaitu sebanyak 23 responden $(54,8 \%)$.

\section{b. Analisa Bivariat}

Tabel 3. Hubungan Tingkat Pendidikan Dengan perilaku ibu dalam melakukan pijat bayi di Desa Baturaja Kecamatan Way Lima Kabupaten Pesawaran

\begin{tabular}{llll}
\hline Pendidikan & Pijat BAyi & Total & P- Value \\
\hline
\end{tabular}




\begin{tabular}{cccccccc}
\hline & \multicolumn{2}{c}{ Tidak Melakukan } & \multicolumn{2}{c}{ Melakukan } & & \\
\cline { 2 - 6 } & $\mathbf{N}$ & $\mathbf{\%}$ & $\mathbf{N}$ & $\mathbf{\%}$ & $\mathbf{N}$ & $\mathbf{\%}$ & \\
\hline Rendah & 5 & 78,9 & 4 & 21,1 & 9 & 100 & 0,003 \\
\hline Sedang & 8 & 44,4 & 0 & 55,6 & 8 & 100 & \\
\hline Tinggi & 0 & 0 & 5 & 100 & 5 & 100 & \\
\hline \multicolumn{1}{c}{ Total } & $\mathbf{3}$ & $\mathbf{5 4 , 8}$ & $\mathbf{9}$ & $\mathbf{4 5 , 2}$ & $\mathbf{4 2}$ & $\mathbf{1 0 0}$ & \\
\hline
\end{tabular}

Pendidikan rendah tidak melakukan pijat bayi $(78,9 \%)$, dan ibu dengan pendidikan sedang tidak melakukan pijat bayi $(44,4 \%)$, dibandingkan ibu yang mempunyai pendidikan tinggi. hasil uji statistik dengan menggunakan chi square didapatkan $p$ value 0,003 yang berarti $p$ value $<\alpha(0,05)$, dengan demikian Ha diterima yang berarti statistik menunjukkan ada hubungan yang bermakna antara tingkat pendidikan dengan perilaku ibu dalam melakukan pijat bayi.

\section{PEMBAHASAN}

Hubungan Tingkat Pendidikan dengan perilaku ibu dalam melakukan pijat bayi di Desa Kecamatan Waylima Kabupaten Pesawaran Tahun 2014. Hasil penelitian dengan menggunakan uji chi square menghasilkan nilai $p$ value $<0,05$ yaitu $p$ value $=0,003$ dengan nilai keeratan sebesar $0,00-0,25$, yang berarti ada hubungan yang bermakna antara tingkat pendidikan ibu dengan perilaku pemijatan bayi.

Pendidikan itu sendiri adalah suatu bimbingan yang diberikan seseorang kepada orang lain agar dapat memahami suatu hal. Tidak dapat dipungkiri bahwa semakin tinggi pendidikan seseorang, semakin mudah pula mereka menerima informasi, dan pada akhirnya pengetahuan yang dimilikinya akan semakin banyak. Sebaliknya, jika seseorang memiliki tingkat pendidikan yang rendah, maka akan menghambat perkembangan sikap orang tersebut Perilaku seseorang dapat dipengarhi oleh faktor predisposisi (predisposing factors) yang mencakup pengetahuan dan sikap masyarakat terhadap kesehatan, tradisi dan kepercayaan masyarakat terhadap hal-hal yang berkaitan dengan kesehatan,sistem nilai yang dianut masyarakat, tingkat pendidikan, tingkat sosial ekonomi, pekerjaan, dan sebagainya. Faktor pendukung (enabling factors), yang meliputi ketersediaan sarana dan prasarana atau fasilitas kesehatan bagi masyarakat, misalnya: air bersih, tempat pembuangan sampah, tempat pembuangan tinja, ketersediaan makanan bergizi, dsb. Termasuk juga fasilitas pelayanan kesehatan seperti puskesmas, rumah sakit, poliklinik, posyandu, polindes, pos obat desa, dokter atau bidan praktek swasta, dan sebagainya. Termasuk juga dukungan sosial, baik dukungan suami maupun keluarga. Faktor penguat (reinforcing factors), yang meliputi faktor sikap dan perilaku tokoh masyarakat (toma), tokoh agama (toga), sikap dan perilaku pada petugas kesehatan. Termasuk juga disini undang-undang peraturan peraturan baik dari pusat maupun dari pemerintah daerah yang terkait dengan kesehatan.

Pijat bayi adalah terapi sentuhan tertua dan terpopuler yang dikenal manusia, yang juga merupakan seni perawatan kesehatan dan pengobatan yang dipraktikkan sejak berabad-abad silam. Sentuhan adalah indra pertama dimana bayi dapat memberikan reaksi. Sentuhan juga merupakan cara anda menyampaikan rasa kasih sayang kepadanya. Mulailah pemijatan sedini mungkin. Makin cepat anda mendapatkan kontak fisik dengan anak, makin cepat keraguan anda lenyap (Prasetyono, 2009). Pijat adalah seni perawatan kesehatan dan pengobatan yang dipraktekkan sejak berabad-abad silam. Bahkan diperkirakan ilmu ini telah dikenal sejak awal manusia diciptakan kedunia (Roesli, 2013). Pijat bayi biasa disebut dengan stimulus touch. Sejak dilahirkan, bayi memiliki tiga kebutuhan yang harus dipenuhi oleh orang tua, yaitu kebutuhan fisik-biologis yang bermanfaat untuk pertumbuhan otak, sistem sensorik serta motoriknya. Sentuhan dan pijat pada bayi setelah kelahiran dapat memberikan jaminan adanya kontak tubuh berkelanjutan yang dapat mempertahankan perasaan aman pada bayi, sehingga pijat bayi merupakan komunikasi yang baik antara ibu dan bayi (Roesli, 2013).

Adapun alasan kenapa pemijatan pada bayi harus dilakukan karena, untuk Bayi Sentuhan alamiah pada bayi sesungguhnya sama artinya dengan tindakan mengurut atau memijat. Kalau tindakan ini dilakukan secara teratur dan sesuai dengan tata cara dan teknik pemijatan bayi, bisa menjadi terapi untuk mendapatkan banyak manfaat untuk buah hati yang anda cintai. Selain itu, sentuhan meningkatkan perkembangan sosial, studi menunjukkan bahwa bayi yang dipijat ketika mereka berusia empat minggu dan sesudahnya, menunjukkan mereka lebih responsif selama waktu pengawasan dirumah dalam kurun waktu dua belas minggu. Lebih dari itu, sentuhan dan pijatan akan mempererat ikatan kasih sayang orang tua dengan anak. Terhadap perkembangan emosi anak, sentuhan orang tua merupakan dasar perkembangan komunikasi, yang akan 
memupuk cinta kasih timbal - balik, lagi pula ia akan merasa aman karena merasa yakin memiliki kasih sayang dan perlindungan orang tua (Roesli, 2013).

Aspek pendidikan disini juga berperah dalam melakukan pemijatan pada bayi maka dari itu dalam penelitian yang dilakukan oleh Laila tahun 2008, seharusnya ibu mendapat pendidikan kesehatan mengenai cara memijat bayi yang diajarkan oleh bidan atau perawat setempat, oleh karena jauh dari jangkauan fasilitas kesehatan maka ibu tidak tahu cara memijat bayi sendiri. Kita ketahui bersama bahwa sikap seseorang didasarkan pada konsep evaluasi berkenaan dengan obyek tertentu dan menggugah motif untuk bertingkah laku.

Penelitian ini sejalan dengan yang dilakukan pleh Rona pada tahun 2010 dengan hasil perhitungan uji statistik menghasilkan nilai $t$ sebesar 29,231 dengan p-value (signifikansi) sebesar 0,000. Adapun nilai ttabel untuk pengujian dengan $\mathrm{a}=0,05$ dan derajat kebebasan df $=31$ adalah sebesar 2,040 . Oleh karena thitung $>$ ttabel $(29,231>$ $2,040)$ atau $\mathrm{p}$-value $<\mathrm{a}(0,000<0,05)$ maka Ha diterima dan H0 ditolak. Dengan demikian dapat diketahui bahwa ada pengaruh pendidikan kesehatan tentang pijat bayi terhadap praktik pijat bayi.

Pendidikan seseorang akan berpengaruh dalam memberikan respon terhadap sesuatu yang datang dari luar. Orang dengan pendidikan tinggi akan memberi respon yang lebih rasional terhadap informasi yang datang dan akan berfikir sejauh mana keuntungan yang mungkin akan mereka peroleh dari pendidikan kesehatan. Selanjutnya pada hubungan sosial, manusia akan saling berinteraksi antara satu dengan yang lain, sebuah keluarga yang berinteraksi secara langsung dengan masyarakat sosial akan lebih besar terpapar informasi seperti tentang pemijatan bayi yang merupakan informasi yang baru yang harus lebih dipahami oleh ibu yang punya bayi khususnya. terhadap penerimaan informasi dan nilai-nilai yang baru diperkenalkan (Mubarak, 2011).

\section{KESIMPULAN}

Pendidikan seseorang akan berpengaruh dalam memberikan respon terhadap sesuatu yang datang dari luar. Orang dengan pendidikan tinggi akan memberi respon yang lebih rasional terhadap informasi yang datang dan akan berfikir sejauh mana keuntungan yang mungkin akan mereka peroleh dari pendidikan kesehatan. Selanjutnya pada hubungan sosial, manusia akan saling berinteraksi antara satu dengan yang lain, sebuah keluarga yang berinteraksi secara langsung dengan masyarakat sosial akan lebih besar terpapar informasi seperti tentang pemijatan bayi yang merupakan informasi yang baru yang harus lebih dipahami oleh ibu yang punya bayi khususnya.

\section{SARAN}

1. Menambah wawasan serta mengembangkan ilmu pengetahuan tentang pijat bayi menjadi lebih baik.

2. Dapat menjadi bahan masukan dan evaluasi khususnya dalam tingkat pendidikan ibu yang masih rendah.

\section{DAFAR PUSTAKA}

Arikunto, Suharsimi. (2010). Proses Penelitian Suatu Pendekatan Praktik. Jakarta: Rineka Cipta.

Budiarto, Eko. (2002). Biostatistika Untuk Kedokteran dan Kesehatan Masyarakat. Jakarta: EGC.

Hapsara, Sunartini. (2012). Kurang Cermat, Pijat Bayi Berisiko Kematian. Di Akses Tanggal 30 April 2012.

Ihsan, Fuad. (2011). Dasar- Dasar Kependidikan. Jakarta: Rineka Cipta.

Mubarak, Wahit Iqbal. (2011). Promosi Kesehatan Untuk Kebidanan. Jakarta: Salemba Medika.

Nestle. (2005). Pentingnya Pijat Bayi. Dikutip dari : https://www.sahabatnestle. co.id/Page/anak/parenting/tips/pentingn ya-pijat-bayi pada tanggal 7 Januari 2013.

Notoatmodjo, Soekidjo. (2003). Metodologi Penelitian Kesehatan. Jakarta: Rineka Cipta.

Notoatmodjo, Soekidjo. (2003). Promosi Kesehatan \& Ilmu Perilaku. Jakarta: Rineka Cipta.

Notoatmodjo, Soekidjo. (2007). Promosi Kesehatan \& Ilmu Perilaku. Jakarta: Rineka Cipta.

Notoatmodjo, Soekidjo. (2012). Promosi Kesehatan Teori \& Aplikasi. Jakarta: Rineka Cipta.

Notoatmodjo, Soekidjo. (2012). Metodologi Penelitian Kesehatan. Jakarta: Rineka Cipta.

Nursalam. (2013). Metodologi Penelitian Ilmu Keperawatan. Jakarta: Salemba Medika.

Pendidikan (UU RI No. 20 Tahun 2003 BAB I, Pasal 1 Ayat 8 tentang Sistem Pendidikan Nasional).

Prasetyono. (2009). Teknik - Teknik Tepat Memijat Bayi Sendiri Panduan Lengkap dan Uraian Kemanfaatannya. Yogyakarta: DIVA Press. 
Roesli, Utami. (2013). Pedoman Pijat Bayi. Jakarta: Trubus Agriwidya.

Safrina, Nora. (2013). Faktor - Faktor yang Mempengaruhi Ibu Tentang Pijat Bayi Di BPS Juniwati Indrapuri Kbupaten Aceh Besar. Diakses Tanggal 28 Juli 2014.

Soyomukti, Nurani. (2010). Teori - Teori Pendidikan. Yogyakarta: Ar - Ruzz Media.

Sugiyono. (2010). Statistika Untuk Penelitian. Bandung: Alfabeta.

Sutanto, Hastono Priyo. (2010). Statistik Kesehatan. Jakarta: Raja Grafindo Persada.

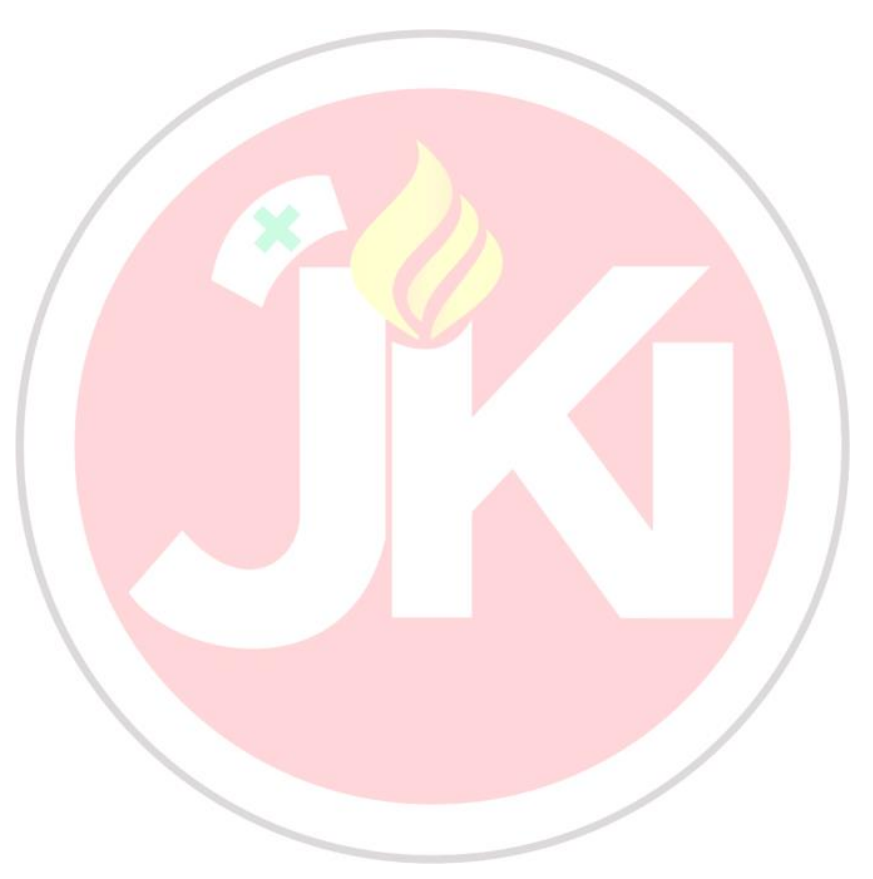

